\title{
Identification of Issues Related to Ergonomics at Construction Site in Malaysia
}

\author{
Nadira Ahzahar, Siti Zubaidah Hashim, Intan Bayani Zakaria and Muhamad Adha Sayuti
}

Faculty of Architecture, Planning and Surveying, Universiti Teknologi MARA, Seri Iskandar Campus, Seri Iskandar, 32610, Perak, Malaysia

Correspondence Author: Nadira Ahzahar, Faculty of Architecture, Planning and Surveying, Universiti Teknologi MARA, Seri Iskandar Campus, Seri Iskandar, 32610, Perak, Malaysia

Received date: 11 April 2018, Accepted date: 25 July 2018, Online date: 8 August 2018

Copyright: (C) 2018 Nadira Ahzahar et al., This is an open-access article distributed under the terms of the Creative Commons Attribution License, which permits unrestricted use, distribution, and reproduction in any medium, provided the original author and source are credited.

\begin{abstract}
Many industries have successfully implemented ergonomic solutions in their facilities as a way to address their workers. Ergonomics is a structured environment to help employees in recognizing their needs and make sure that equipment and tools, the tasks and the environment can work together. Ergonomic helps in work efficiency and lead to productivity increment as well. Unfortunately, beyond the success of the construction industry in Malaysia, ergonomic awareness is still very much lacking since many employers neglect it as a part of the worker's needs. Ergonomic should be emphasized among the entire workers in construction sector since the construction sector is a risky sector which leads to high level of injuries and death. Therefore, this paper attempts to identify common issues related to ergonomics in construction site in Malaysia. The opinions and views of related parties in construction site were obtained from structured interviews and questionnaires to give a clearer picture of the current situation. The common issues related to ergonomics in construction site can be categorized into three main group which are; Legislation; Handtools and Working Posotion. Apart from that, the findings also indicated Hand Wrist or Arm Musculoskeletal Disorder (HWAMD), Shoulder Musculoskeletal Disorder (SMD) and Low Back Pain (LBP) are most frequent construction illness or injuries. Welders and carpenters were identified as most affected workers in construction site. Nonetheless, this paper also suggests various ways to increase awareness in ergonomic among construction parties to promote safer and healthier environment for all
\end{abstract}

Key words: Ergonomics · Construction Site · Legislation · Handtools · Working Position· Construction Illness/Injuries.

\section{INTRODUCTION}

Construction is an industry that is very physically demanding. The construction work can be performed at a variety of different sites ranging from buildings and highways to demolition sites and tunnel excavations. Workers on the job operate a variety of tools and must control machines, move heavy objects, repair equipment, as well as monitor processes. Workers in construction industry are exposed high level of injuries and pain due to risky nature of works in construction site. Furthermore, construction workers who are frequently stressed about work-related injuries and pain and often fail to seek help, putting themselves at risk for more injuries and mental health issues, including depression, anxiety, and even suicide. This pilot study shows the high prevalence of substantial mental distress in the U.S. construction worker population, and how this distress is strongly related to pain and injuries. [1]

This problem has been studied in United States of America, but it might also happen to the construction site in Malaysia. Injuries and pain often happen to the construction worker but not all of it has been reported to their employer. The main issue here was they don't realize the main factor why do they feel the pain or how the pain happened. Many construction workers only seek for medicine to cure their pain, but they didn't make any initiative to find the problem and rectify it to evade the pain from reoccurence. Therefore, this paper attempts to identify common ergonomics issues in Malaysian construction industry.

\section{Literature Review:}

The International Ergonomics Association (IEA) state that "Ergonomics (human factors) is the scientific discipline concerned with the understanding of interactions among humans and other elements of a system and the profession that applies theory, principles, data and methods to design in order to optimize human well-being and overall system performance”. [2] Ergonomic also can be described as a situation when a labour doing his job in a suitable position depends on his comfort with suitable tools and will never cause any injury or trouble for him. while non-ergonomic can be described as a situation where a labour doing his job in an uncomforted position with unsuitable tools and will cause injuries for him weather in short time or long-time period. Ergonomic in general, combines the comfort and safety of user.

The ergonomic issue in construction industry is not relatively new but somehow the implementation is still much lacking compared to other industries. The ergonomic related issues in construction can be categorised into three groups which are Legislation; Hand Tools; and Working Position.

\section{Legislation:}

Since the construction industry is quite challenging, there is global organization which is Occupational Safety and Health Administration (OSHA) that provide a safety and health guildelines for construction workers. OSHA has suggested the ergonomics programme which focused on Engineering Control; Administrative and Work Practice Controls; and Personal Protective Equipment [3]. 
Engineering controls is unlike other controls that generally focus on the employee exposed to the hazard. The basic concept behind engineering controls is to the extent feasible, work environment and the job itself should be designed to eliminate hazards or reduce exposure to hazards. Engineering controls implement a physical change to the workplace which eliminates or reduces hazard on the job or task. [3]. The example of engineering control is such use a device to lift and reposition heavy objects to limit force exertion, reducing the weight of a load to limit force exertion, reposition a work table to eliminate a long reach object and enable working in neutral postures, use diverging conveyors off a main line so that tasks are less repetitive, or reaching and redesign tools to enable neutral postures.

Work practice controls reduce the likelihood of exposure by altering the manner in which a task is performed. Administrative controls include education, training, and application of Standard Operating Procedures. [3] The combination of these two factors will establish the efficient processes and procedures. The example of Administrative and Work Practice Controls are requiring the heavy loads are only lifted by two people to limit force exertion, establishing systems so workers are rotated away from tasks to minimize the duration of continual exertion, repetitive motions, and awkward postures, design a job rotation system in which employees rotate between jobs that use different muscle groups, staff "floaters" to provide periodic breaks between scheduled breaks and properly use and maintain pneumatic and power tools.

Personal Protective Equipment (PPE) is equipment worn to minimize exposure to serious workplace injuries and illnesses. [3] The PPE is also worn to reduce exposure to ergonomics-related risk factors. These injuries and illness may come from contact with chemical, radiological, physical, electrical, mechanical, or other workplace hazards. Example of PPE equipment are such as gloves, safety glass, shoes, earplugs, hard hats, respirators, vests and full body suits. The example of the uses of PPE in workplace are such using padding to reduce direct contact with hard, sharp, or vibrating surfaces and wearing good fitting thermal gloves to help with cold conditions while maintaining the ability to grasp items easily.

Hand Tools:

Construction workers usually spend a lot of time gripping tools and materials with their hands. Gripping tools and material can put stress on their hand and causing discomfort and pain which may develop a serious muscle or joint injury. Their ability to use hands and wrists may be reduced and worsen, they may even become permanently disabled. Putting a forceful grip on tools and bend wrist when using it may put a construction worker at risk of injury. Besides, moving wrist rapidly and repetitively also may cause injury to hand. Injuries also may result if a worker hold vibrating tools and often handles tools that are sharp or hard press into their hand, wrist or arm. If a worker feels the pain and continue doing the work or task without allowing their muscles and tendons to rest and heal, the pain may become worse and it could lead to a serious injury that they didn't noticed. One solution for the problems that the construction worker faced when using tools is using an ergonomics tools that fit the job. Some of the construction tools have been labelled as ergonomic tools when it is sold at the hardware store, but it is depending on the user to determine how comfort when they use the tools. A tool can be considered as ergonomics when it fit the task you do, fits your hand, allows a good grip, takes less effort, does not require you to work in awkward position, does not dig into your fingers or hand and comfortable and effective. Nevertheless, a tool designed for one task may put more stress on the hand or wrist when used for a different task [4].

\section{Working Position:}

Construction works need many skills and working position. Eventually, some of the skills and working position that the workers applied to do the job is not in the ergonomic methods and will cause pain to them and overtime lead to a serious injury [5]. Belows are examples of working position that normally used by a construction worker that is causing risk and the solution provided by the National Institute of Occupational Safety and Health to reduce the risk of pain [6].

i) Stoop and Kneels:

Some construction works need a worker to work close to the ground or floor. For an example, a worker may have to stoop or kneel when installing or finishing slabs, decks or floor covering and finishes. Bending, stooping, kneeling or squatting can cause pain to the worker lower back or knees. In a long time, the worker is developing a serious muscle or joint injuries. The worker risk is higher if he did the stooping kneeling, or squatting movement repetitively or for a long period of time.

\section{ii) Overhead Work:}

Some construction works need the worker to do the overhead work that need boths of their arms be raised to reach the task. Their head may be looking up to see the task. The task may be drilling, driving fastener or finishing drywall. An overhead works put the stress on the worker shoulder and neck. This stress may lead to a serious injury on muscle and joint.

\section{Ergonomic Related Illness/Injuries:}

Ergonomic study gives a huge impact to the construction worker. With ergonomics, they learn that a working position give so much impact for them and each hand tools that they use have a limit with its function but still can be modified to suit with their tasks. For each non-suitable hand tools, they used and nonergonomic working position that they work may give a negative impact to themselves such as belows;

\section{i) Musculoskeletal Disorders (MSD):}

Musculoskeletal disorders (MSD) are some of the most common forms of ill health in construction. The term MSD covers any injury, damage or disorder of the tissues including joints, ligaments, muscles, nerves and structures that support limbs and neck. [7]

ii) Neck Musculoskeletal Disorder (NMD):

Most of the studies reviewed defined "repetitive work" for the neck as work activities which involve continuous arm or hand movements which affect the neck/shoulder musculature and generate loads on the neck/shoulder area. Therefore, the Neck Musculoskeletal Disorder (NMD) can be concluded as an occurrence that is caused by the repetitive work at human shoulders and arms. Many of the neck musculoskeletal disorder studies are not separated with other part of bodies. In the other hand, most of it was include with other part of bodies which are reducing the explanation about Neck Musculoskeletal Disorder [8]. For example, in construction site, workers who are exposed to NMD which repetitive use of shoulder and arm are electrician, roofer, bricklayer and painter.

iii) Shoulder Musculoskeletal Disorder (SMD):

Human shoulders are the most movable joints in their body. Shoulder joint may become unstable because the ball of the upper arm is larger than the shoulder socket that holds it. As the shoulder can be unstable, many common problems may happen such as sprains, strains, dislocations, separations, tendinitis, bursitis, torn rotator cuffs, frozen shoulder, fractures and arthritis. [8] Shoulder pains and injuries are usually as the result of overworking the shoulder. When a worker keeps his arm raised above his shoulder or keep his arm stretched out, he will begin to fill the ache after a short time.

iv) Elbow Musculoskeletal Disorder (EMD):

Human elbow joint is made up of bone, cartilage, ligaments and fluid. When any of these, hurted or injured, it can be considered as an elbow problem. Many works can be the cause of elbow hurt. A common cause is tendinitis, which is an inflammation or injury to the tendons that attach muscle to bone. Besides, tendinitis also may occur by the overuse of the elbow. [8] The example of work in construction industry that relates with this pain is when an unskilled worker is carrying a heavy material and placed it on the high place, he might use a huge force of his elbow when he raises up his hand and hold the heavy material to put at the high place. 
v) Hand, Wrist or Arm Musculoskeletal Disorder (HWAMD):

This type of pain involves nerve, tendons, muscles and supporting structures such as intervertebral discs. The example of the disease that attacking at this body part are De Quervain's Disease, Trigger Finger, Carpal Tunnel Syndrome, Guyon's Syndrome, Cubital Tunnel Syndrome, Hand-Arm Vibration Syndrome and Raynaud's Phenomenon. [9] This type of pain is caused by fixed and awkward postures. The position of the hand, wrist and arm are at the wrong than normal position which is including repetitive movements, mechanical stress, forceful work and vibratory instruments. The example of work that relates with construction industry is when a worker is using the unsuitable hand tools such using a plyer instead of spanner to tighten bolt and nuts, this will lead to an awkward hand position.

vi) Low Back Pain (LBP):

Back pain is a pain that felt in the back of a human body that usually caused by muscles, nerves, bones, joints or other structures in the spine. Back pain may have a sudden feeling of pain or can be a chronic pain. It also may feel constant or intermittent, stay in one place or spread to other areas. It may be a dull ache, sharp ache, piercing or burning ache. The pain may spread into the arms and hands as well as the legs or feet and may include symptoms other than pain. These symptoms may include tingling, weakness or numbness. The back pain can be divided into neck pain, middle back pain, lower back pain and tailbone pain. Low back pain is defined as a pain, muscle tension, or stiffness located below the costal margin and above the inferior gluteal folds, with or without leg pain (sciatica) [10]. Low back pain can occur suddenly or develop in a period of time. It will happen when workers do sudden quick movements especially while handling or lifting a heavy object and it will lead to painful muscle strains. The example of work related is when worker is stooping to carry a heavy load material. When he stoops and lift the heavy material by sudden quick movement, it may cause low back pain.

Research Methodology:

This paper achieves the objectives from the literature and through questionnaires and interviews. This paper using two categories of data; primary and secondary data. Primary data is data obtained directly from actual work situation. Among the techniques used to obtain primary data is like using questionnaires and interviews. Secondary data is information from existing materials and can be obtained through reference library. It involves research texts, documents, papers, mass media, and so on. The technique chosen is quantitative where more than 60 sets questionnaires have been distributed to the three different districts of construction sites which are in Seri Iskandar, Ipoh and Sungkai. The collected data were analyzed using the Statistical for Social Science (SPSS). Frequency analysis is obtained from the SPSS output and average index method is adopted for analysis from the result of frequency analysis. The frequency and the percentage will be representing in the form of related table and chart.

\section{RESULTS \& DISCUSSION}

Identify Common Issues Related to Ergonomic in Construction Site:

Table 1 shows the common issues that related to the ergonomic in legislation. These questions are carried out to identify the construction worker's knowledge and understanding on legislation implemented in Malaysia. Surprisingly, all the questions achieved agreed index means that construction site in Malaysia practicing good OSHA implementation and they are well recognizing with the legislation provided by the government. From the analysis done, the highest index is the issue of Personal Protective Equipment (PPE) is helpful where it achieved 4.50 of mean value index. It indicated that most of construction workers have a significant knowledge and understanding of PPE helpful in safety at site. Although their level of knowledge is not comprehensive, but they know about the risk of accidents at construction sites. The relation of Personal Protective Equipment (PPE) as part of ergonomic issues is the importance of wearing selfprotection for all workers while being in construction site.

Table 1: Table of rank for Legislation Issue Issue of Ergonomics at Construction Site.

\begin{tabular}{|l|l|l|l|}
\hline Legislation & Items & Index & Mean \\
\hline 1 & Personal Protective Equipment helps to minimize workplace injuries. & 4.50 \\
\hline 2 & Engineering Control is useful when working on site. & 4.38 & Agree \\
\hline 3 & Personal Protective Equipment is important to be equipped. & 4.35 & 4.20 \\
\hline 4 & Application of Standard Operating Procedures is helpful. & 4.17 & Agree \\
\hline 5 & Work Practise Control is helpful to be used. & 4.17 \\
\hline 7 & Supervisor trains you to implement engineering control. & Agree & Agree \\
\hline
\end{tabular}

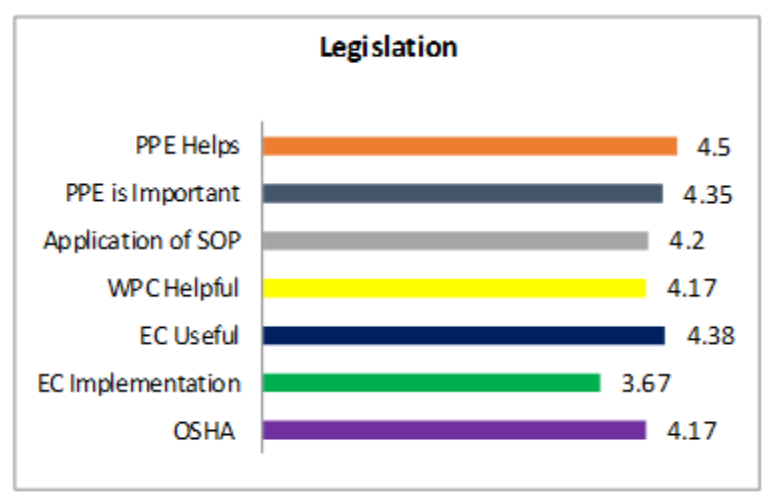

Table 2 shows the common issues that related to the ergonomic in hand tools usage as it is one of the important materials to be equipped by construction workers. From the analysis done, the issue of Perform Faster with Fit Tools achieved highest mean value index of 4.37 . This issue is the most agreed issue as the 
Citation: Nadira Ahzahar, Siti Zubaidah Hashim, Intan Bayani Zakaria and Muhamad Adha Sayuti. Identification of Issues Related to Ergonomics at Construction Site in Malaysia. Advances in Natural and Applied Sciences., 12(8): 21-25. DOI: 10.22587/anas.2018.12.8.4

construction worker know the advantages of using the ergonomic tools where they can enhance their ability to work faster and avoid from delayed task. The relation of this issue with ergonomic is the fit tools is the ergonomic tools. There are many ergonomic labelled tools sold for construction worker to avoid them from feel any pain or facing any problem during working. It is only depending by the company to equip them with it or not.

Lastly for working position, most of the workers agree that they want their supervisor to monitor and suggest best work practise which scored the highest mean value with 4.48 as shown in the Table 3 .

Table 2: Table of rank for Handtool Issue of Ergonomics at Construction Site

\begin{tabular}{|l|l|l|l|}
\hline \multicolumn{2}{|l|}{ Handtools } & Mean & \\
\hline 1 & Worker can perform faster when they used tools that fit with their task. & 4.37 & Agree \\
\hline 2 & $\begin{array}{l}\text { Worker fit with tools that have been labelled as ergonomic tools. } \\
\text { Hand tool designed for one task may put some stress on hand or wrist when used for } \\
\text { a different task. }\end{array}$ & 3.90 \\
\hline 3 & \begin{tabular}{l} 
Agree \\
\hline
\end{tabular}
\end{tabular}

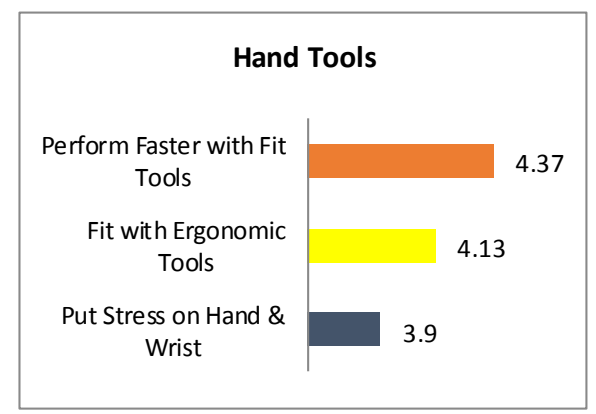

Table 3: Table of rank for Working Position Issue of Ergonomics at Construction Site.

\begin{tabular}{|l|l|l|}
\hline Working Postitions & Mean & \\
\hline Items & 4.48 & Index \\
\hline Supervisor monitors and suggests the best work practise. & Agree \\
\hline $\begin{array}{l}\text { Stooping, kneeling and doing overhead work repetitively make workers feel } \\
\text { discomfort. }\end{array}$ & 4.37 & Agree \\
\hline Worker try to alter their tools to avoid from stoop, kneel and doing overhead job. & 4.17 & Moderate \\
\hline Workers endure their pain and continue working to finish their job. & 2.97 & \\
\hline
\end{tabular}

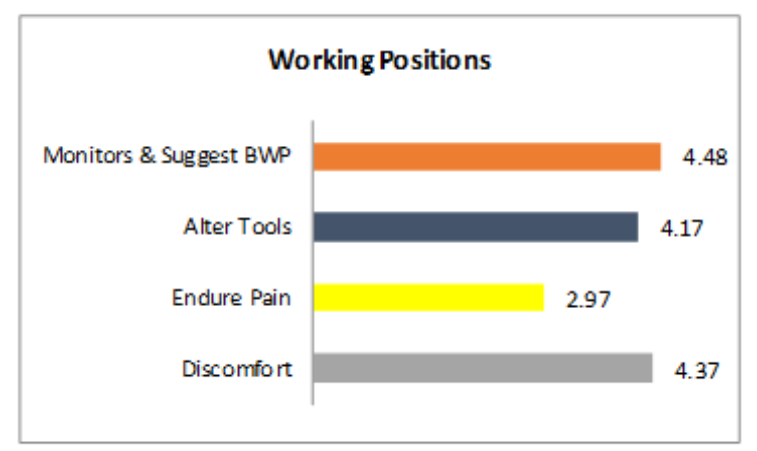

There are four (4) questions provided This type of questions is carried out to identify which problem was the most occurred faced by the respondents while working. From the analysis done, highest mean is Monitors \& Suggest Best Work Practise (BWP) with mean value index of 4.48. This is because, workers need their supervisor to monitor them to know did they do it properly or whether the work method and practise is suitable or not. Construction worker want their supervisor to monitor and suggests best work practise of their work to avoid from a wrong working position that could bring pain to them. This is because many of the respondents are still new and they rely on supervisor to monitor their work. The relation of this issue with ergonomic is best work practise help worker to work in a best way includes working position and step to do the work. This is an ergonomic type of work and make worker feel comfort to do their work. The only question that achieve moderate index is Endure Pain where it achieves mean value index of 2.97. This is because the respondent doesn't know which level of the pain that they feel. If the pain is small they will continue their job and if the pain is critical they will surely stop and make a report to the management unit.

Identify Injury/Illness Related to Ergonomic in Construction Site:

From the survey done, there are few types of injury or illness that related to non-ergonomic working procedure were identified. It is found that the most possible pain that will affect the construction workers are Hand Wrist or Arm Musculoskeletal Disorder (HWAMD), Shoulder Musculoskeletal Disorder (SMD) and Low Back Pain (LBP) as shown in the Table 4.

Besides that, from the analyisis done, the most affected workers with injuries in construction industries are Welder and Carpenter. This finding is identified from the percentage of injury/illness by each worker as shown on the Table 5 . 
Citation: Nadira Ahzahar, Siti Zubaidah Hashim, Intan Bayani Zakaria and Muhamad Adha Sayuti. Identification of Issues Related to Ergonomics at Construction Site in Malaysia. Advances in Natural and Applied Sciences., 12(8): 21-25. DOI: 10.22587/anas.2018.12.8.4

Table 4: Types of injury/illness most affecting construction workers.

\begin{tabular}{|l|l|l|l|}
\hline No & Type of Illness & Index & Percentage \\
\hline 1 & Shoulder Musculoskeletal Disorder (SMD). & $(90 \%)$ & Yes \\
\hline 2 & Hand, Wrist, Arm Musculoskeletal Disorder (HWAMD). & $(90 \%)$ \\
\hline 3 & Low Back Pain (LBP). & Yes & $(77 \%)$ \\
\hline
\end{tabular}

Table 5: Type of workers that most affecting with illness/ injuries.

\begin{tabular}{|l|l|ll|}
\hline No & Workers & Type of Illness/Injuries \\
\hline 1 & Welder & $1)$ & Shoulder Musculoskeletal Disorder (SMD) \\
& & $2)$ & Hand, Wrist or Arm Musculoskeletal Disorder (HWAMD) \\
\hline 2 & Carpenter & $1)$ & Shoulder Musculoskeletal Disorder (SMD) \\
& & $2)$ & Hand, Wrist or Arm Musculoskeletal Disorder (HWAMD) \\
\hline
\end{tabular}

Lastly, this study also found that the construction workers are well satisfied with the facilities provided by their employer. However, it is found that some of them have a moderate feeling with the cleanliness of their working area which scored lowest mean value with 3.28 as shown on the table 6 .

Table 6: Table of Rank for Means Employees Satisfaction.

\begin{tabular}{l} 
Table 6: Table of Rank for Means Employees Satisfaction. \\
\hline Employees Satisfaction
\end{tabular}

\section{Conclusion:}

There are many issues identified in ergonomics in Malaysia's construction site. Mainly the issues have been categorized into three goup; Legislation, Hand tool and Working Position. For Legislation issue that are related with ergonomic at construction site are well known by the construction workers meaning the level of awareness of worker are relatively high. Besides, they also are committed with the usage of ergonomic hand tools as the most popular issue which they knew they may perform faster with fit tools. Apart from that for working position issue, construction workers want their supervisor to monitor and suggests best work practise of their work. This shows that they are committed with ergonomic working procedure. The findings also indicated Hand Wrist or Arm Musculoskeletal Disorder (HWAMD), Shoulder Musculoskeletal Disorder (SMD) and Low Back Pain (LBP) are most frequent construction illness or injuries. Welders and carpenters were identified as most affected workers in construction site. Relevant efforts and measures should be implemented to improve the ergonomics implementation in Malaysia. The ways that can be suggested are government may impose mandatory policy of the usage of ergonomic tools in construction site among workers and employer also should provide an Occupational Doctor Service in contract until the the completion of project to ensure workers pain and diseases are treated professionally.

\section{REFERENCES}

[1] Jacobsen, H.B., M. Caban, D.O. Alberto, Onyebeke, C. Lynn, Sorensen, Glorian, Dennerlein, T. Jack Reme and E. Silje, 2013. Construction Workers Struggle with a High Prevalence of Mental Distress, and This Is Associated with Their Pain and Injuries. Journal of Occupational and Environmental Medicine, 55(10): 1197-1204.

[2] Jan Dul, Ralph Bruder, Peter Buckle, Pascale Carayon, Pierre Falzon, William S. Marras, John R. Wilson and Bas van der Doelen, 2012. A strategy for human factors/ergonomics: developing the discipline and profession. Journal of Ergonomics, 55(4): 377-395.

[3] https://www.osha.gov/SLTC/ergonomics/controlhazards.html

[4] Albers, J.T., C.F. Estill, 2007. Simple solutions: ergonomics for construction workers. Journal of Immunology, 122.

[5] Barjasteh, M., 2014. Ergonomic Methods to Improve Safety in the Construction Sector and Reduce Costs. Degree Thesis of Industrial Engineering; Bachelor of Science. California Polytechnic State University, San Luis Obispo.

[6] https://www.osha.gov/Publications/osha3125.pdf

[7] Buckle, P., 2014. Work-Related Neck and Upper Limb Musculoskeletal Disorders (1st ed.). European Agency for Safety and Health at Work.

[8] Bernard, B.P., V. Putz-Anderson, 1997. Musculoskeletal disorders and workplace factors; a critical review of epidemiologic evidence for work-related musculoskeletal disorders of the neck, upper extremity, and low back. National Institute for Occupational Safety and Health Series: DHHS Publication; no. (NIOSH), 97-14.

[9] Mark, G., Boocock, M.K. Jill, Collier, J. Peter, McNair, Marian Simmonds, J. Peter, Larmer and Bridget Armstrong, 2009. A Framework for the Classification and Diagnosis of Work-Related Upper Extremity Conditions: Systematic Review. Seminars in Arthritis and Rheumatism, 38(5): 407-408.

[10] Manek, N.J., A.J. MacGregor, 2005. Epidemiology of back disorders: prevalence, risk factors, and prognosis. Current Opinion in Rheumatology: Journals.lww.com, 17(2): 134-140. 